EESTI NSV TEADUSTE AKADEEMIA TOIMETISED. XV KÖIDE FOOSIKA-MATEMAATIKA- JA TEHNIKATEADUSTE SEERIA. 1966, NR. 2

ИЗВЕСТИЯ АКАДЕМИИ НАУК ЭСТОНСКОЙ ССР. ТОМ ХV СЕРИЯ ФНЗНКО-МАТЕМАТИЧЕСКИХ И ТЕХНИЧЕСКИХ НАУК. 1966, № 2

Я.-М. ПУННИНГ, А. ЛИИВА, Э. ИЛЬВЕС

\title{
УСОВЕРШЕНСТВОВАННАЯ МЕТОДИКА ОПРЕДЕЛЕНИЯ АБСОЛЮТНОГО ВОЗРАСТА ПО ПРИРОДНОМУ РАДИОУГЛЕРОДУ
}

Измерение природного радиоактивного углерода $\left(\mathrm{C}^{14}\right)$ имеет в настоящее время. большое практическое значение в связи с широким использованием этого метода при определении абсолютного возраста геологических, археологических и других объектов.

Применяемый в Институте зоологии и ботаники АН ЭССР усовершенствованныйвариант сцинтилляционного метода Р. Прингля [1] позволяет успешно датировать образцы возрастом до 28500 лет [2].

Повышение точности датировок и расширение диапазона определяемого возраста может быть достигнуто за счет применения бензола в качестве носителя активности естественного $\mathrm{C}^{14}$. Помимо хороших сцинтилляционных свойств бензол обладает и высоким содержанием углерода (92 вес.\%).

\section{I. СИНТЕЗ БЕНЗОЛА ИЗ ПРИРОДНЫХ УГЛЕРОДСОДЕРЖАЩИХ МАТЕРИАЛОВ}

\section{1. Общие сведения о синтезе бензола и применяемых катализаторах}

Синтез бензола из углерода путем тримеризации ацетилена осуществлен несколькими авторами. Характерные данные некоторых типичных синтезов приведены в табл. 1.

Таблица 1

\begin{tabular}{|c|c|c|c|c|}
\hline \multirow[b]{2}{*}{ Aвтор } & \multirow[b]{2}{*}{$\begin{array}{l}\text { Характеристика синтеза и } \\
\text { применяемый катализатор }\end{array}$} & \multicolumn{2}{|c|}{ Условия синтеза } & \multirow[b]{2}{*}{$\begin{array}{c}\text { Выход, } \\
\%\end{array}$} \\
\hline & & $\begin{array}{l}\text { темпе- } \\
\text { ратура, } \\
{ }^{\circ} \mathrm{C}\end{array}$ & $\begin{array}{c}\text { давле- } \\
\text { ние, } \\
\text { атм }\end{array}$ & \\
\hline $\begin{array}{l}\text { Майер }{ }^{[3]} \\
\text { Зелинский }\left[{ }^{4}\right] \\
\text { Реппе }\left[{ }^{5}\right] \\
\left.\text { Шапиро и Вейс }{ }^{6}\right] \\
\left.\text { Таммерс и др. }{ }^{7}\right] \\
\left.\text { Лютц }{ }^{8}\right] \\
\text { Старик и др. }\left[{ }^{9}\right]\end{array}$ & $\begin{array}{l}\text { Пирогенная конденсация } \\
\text { Контактный пиролиз } \\
\mathrm{Ni}(\mathrm{CO})_{2}-\left[\left(\mathrm{C}_{6} \mathrm{H}_{5}\right)_{3} \mathrm{P}\right]_{2} \\
\Gamma_{\text {удри } \mathrm{M}-46, \mathrm{~B}_{2} \mathrm{H}_{6}} \\
\text { Пиролиз } \\
\left(\mathrm{C}_{2} \mathrm{H}_{5}\right)_{3} \mathrm{Al}-\mathrm{TiCl}_{4} \\
\left(\text { uзо-C }{ }_{4} \mathrm{H}_{9}\right)_{3} \mathrm{Al}^{-\mathrm{TiCl}_{4}}\end{array}$ & $\begin{array}{c}550-900 \\
650 \\
60-70 \\
600 \\
23-39 \\
-8\end{array}$ & $\begin{array}{c}\text { Норм. } \\
\text { 10 } \\
\text { Норм. } \\
\text { " } \\
\text { " }\end{array}$ & $\begin{array}{l}-25 \\
88 \\
50 \\
30 \\
49,1 \\
72\end{array}$ \\
\hline
\end{tabular}

Как следует из приведенных в таблице данных, наиболее высокие выходы бензола (за исключением метода Реппе) были получены при использовании алюмиєийорганических катализаторов. 
Главным недостатком синтеза по Реппе является то, что работа с ацетиленом при высоких давлениях связана с взрывоопасностью и требует сложной аппаратуры. Использование же алюминийорганических џиглеровских катализаторов позволяет проводить тримеризацию в мягких условиях (нормальное давление, невысокая температура).

Синтезы полимеров с циглеровскими катализаторами имеют большое практическое значение и описаны в многочисленных работах. В то же время синтезы циклизации ацетиленовых углеводородов, обладающие главным образом препаративным характером, исследованы пока мало.

Циглеровские катализаторы состоят из катализатора (соединение металла IV-VI групп, например, $\mathrm{TiCl}_{4}$ ) и сокатализатора (алюминийорганическое соединение), которые в отдельности каталитических свойств не имеют. Процесс образования активнодействующего катализатора в растворителе представляет собой довольно сложную реакцию, которая, завися от концентрации компонентов, может осуществляться различными путями $\left[{ }^{10}\right]$. При различных молярных отношениях $\mathrm{AlR}_{3} / \mathrm{TiCl}_{4}$ реакции между компонентами катализатора происходят по-разному:

1. $\mathrm{AlR}_{3} / \mathrm{TiCl}_{4}=2: 1$

$2\left(\mathrm{C}_{2} \mathrm{H}_{5}\right)_{3} \mathrm{Al}+\mathrm{TiCl}_{4} \rightarrow 2\left(\mathrm{C}_{2} \mathrm{H}_{5}\right)_{2} \mathrm{AlCl}+\left(\mathrm{C}_{2} \mathrm{H}_{5}\right)_{2} \mathrm{TiCl}_{2}$

2. $\mathrm{AlR}_{3} / \mathrm{TiCl}_{4}=1: 1$

$$
\left(\mathrm{C}_{2} \mathrm{H}_{5}\right)_{3} \mathrm{Al}+\mathrm{TiCl}_{4} \rightarrow\left(\mathrm{C}_{2} \mathrm{H}_{5}\right)_{2} \mathrm{AlCl}+\mathrm{C}_{2} \mathrm{H}_{5} \mathrm{TiCl}_{3}
$$

3. $\mathrm{AlR}_{2} / \mathrm{TiCl}_{4}=1: 2$

$$
\left(\mathrm{C}_{2} \mathrm{H}_{5}\right)_{3} \mathrm{Al}+2 \mathrm{TiCl}_{4} \rightarrow \mathrm{C}_{2} \mathrm{H}_{5} \mathrm{AlCl}_{2}+2 \mathrm{C}_{2} \mathrm{H}_{5} \mathrm{TiCl}_{3}
$$

В. Солтман и др. $\left[{ }^{11}\right]$, проводя анализ комплекса, образовавшегося при смешивании триизобутилалюминия с четыреххлористым титаном, нашли, что практически весь титан в осадке находится в восстановленном состоянин.

К. Маковецкий $\left.{ }^{12}\right]$, изучая циклизацию дериватов ацетилена, нашел, что при увеличении отношения $\left(u з о-\mathrm{C}_{4} \mathrm{H}_{9}\right)_{3} \mathrm{Al} / \mathrm{TiCl}_{4}$ выходы достигают максимального значения при отношении $3: 1$, а затем снижаются, благодаря восстанавливающим свойствам (uзо- $\left.\mathrm{C}_{4} \mathrm{H}_{9}\right)_{3} \mathrm{Al}$.

Б. Францус и др. $\left.{ }^{13}\right]$ получили оптимальные выходы при стношениях $\mathrm{AlR}_{3} / \mathrm{TiCl}_{4} 1: 1,75$ - $1: 2,25$. Конечный продукт реакции между компонентами катализатора зависит и от времени процесса. Найдено, что содержание алкилтитанхлорида в растворе катализатора постепенно уменьшается. Его содержание можно повысить прибавлением небольших количеств кислорода [10].

В качестве растворителей при образовании активнодействующего катализатора, составляющих среду реакции полимеризации и увеличивающих дисперсность катализатора, можно применять как алифатические, так и ароматические углеводороды. Принято считать $\left[{ }^{12}\right]$, что природа и количество растворителя не оказывают влияния на выход продукта реакции.

Много разногласий существует по вопросу о механизме действия катализатора. Высказывается міение [14], что активнодействующий катализатор представляет собой твердую фазу, состояшую из $\mathrm{TiCl}_{3}$, поверхность которого покрыта адсорбированным $\left(u з о-\mathrm{C}_{4} \mathrm{H}_{9}\right), \mathrm{Al}$.

Э. Бадин $\left.{ }^{15}\right]$ считает инициаторами полимеризации свободные радикалы, образующиеся при гомолитическом распаде титаноорганических соединений: $\mathrm{RTiCl}_{3} \rightarrow \mathrm{R}+\mathrm{TiCl}_{3}$. 
Д. Ладлам и др. $\left[{ }^{16}\right]$ утверждают, что активнодействующий катализатор содержит титан низших валентностей, преимущественно двухвалентный. При распаде алкильных производных титана по радикальному механизму получаются соединения титана низших валентностей, например RTiCl, которые и играют роль катализатора.

По мнению Э.Лютца $\left.{ }^{8}\right]$, суть механизма циклизации состоит в поверхностном катализе. Ацетилен, хемосорбируясь на катализаторе, поляризуется и образует линейный полимер или входит в цикл.

К. Маковецкий $\left[{ }^{12}\right]$ считает, что образование циклических тримеров гредставляет собой $\pi$-комплексную многоцентровую реакцию.

\section{2. Методика синтеза}

В данной работе для получения бензола применялась следующая схема синтеза [9]:
1) органические образцы $\underset{\text { вакуум }}{\stackrel{600^{\circ}}{\rightarrow}} C^{*}$
2) a) $2 \mathrm{C}^{*}+\mathrm{Ca} \rightarrow \mathrm{CaC}_{2} *$
б) $2 \mathrm{C}^{*}+2 \mathrm{Li} \rightarrow \mathrm{Li}_{2} \mathrm{C}_{2} *$
3) a) $\mathrm{CaC}_{2}{ }^{*}+2 \mathrm{H}_{2} \mathrm{O} \rightarrow \mathrm{Ca}(\mathrm{OH})_{2}+\mathrm{C}_{2} * \mathrm{H}_{2}$
б) $\mathrm{Li}_{2} \mathrm{C}_{2}^{*}+2 \mathrm{H}_{2} \mathrm{O} \rightarrow 2 \mathrm{LiOH}+\mathrm{C}_{2} * \mathrm{H}_{2}$
4) $3 \mathrm{C}_{2} * \mathrm{H}_{2} \stackrel{\left(\text { uзo- } \mathrm{C}_{4} \mathrm{H}_{9}\right)_{3} \mathrm{Al}-\mathrm{TiCl}_{4}}{-10^{\circ} \mathrm{C}} \mathrm{C} *{ }_{6} \mathrm{H}_{6}$

А. Синтез карбида. Предварительная обработка исследуемых образцов, состоящая из механической очистки, разложения карбонатных примесей, выделения гуминовых веществ и обугливания в вакууме, описана в статье [17].

Из полученного углерода синтезируется карбид, дающий при разложении водой ацетилен. Для этой цели применимы карбиды, которые могут быть представлены как продукты замещения водорода в ацетилене металлами. Они образуются, главным образом, из элементов I и II группы периодической системы. Карбиды щелочных металлов и магния имеют сравнительно низкую температуру распада $\left(\mathrm{Na}_{2} \mathrm{C}_{2} \sim 400, \mathrm{Li}_{2} \mathrm{C}_{2} \sim\right.$ $\sim 600$ и $\mathrm{MgC}_{2} \sim 800^{\circ} \mathrm{C}$ ), что необходимо учитывать при синтезе карбида при помощи указанных металлов.

Синтез карбида лития проводился в реакторе из нержавеющей стали. Обугленный и измельченный образец смешивают в тигле из нержавеющей стали с литием в молярном отношении $1: 1$. Тигель закрывают крышкой и помещают в реактор. После герметизации реактора из него откачивают воздух, наполняют аргоном и нагревают в муфельной печи. Начало образования карбида отмечалось при температурах около $400^{\circ} \mathrm{C}$. Быше $600^{\circ}$ наблюдалось разложение карбида лития на элементы, что согласуется с данными литературы [18].

Лучшие выходы карбида были получены нагреванием реакционной смеси при температурах $500-550^{\circ}$ в течение $15-30$ мин. Выход карбида зависит при этом от характера образца, достигая в некоторых случаях $\sim 100 \%$. 
Преимущество описанного метода состоит в относительно низкой температуре и, что особенно важно при серийных определениях, кратковременности процесса карбидизации.

Синтез карбида кальция [19] проводился аналогично вышеописанному синтезу карбида лития, но нагревание реакционной смеси велось при температуре $1000-1050^{\circ}$ в течение 30 мин. Для повышения выхода карбида кальций был взят с избытком. При этом выходы достигли $85-95 \%$ по углероду.

Б. Разложение карбида. Полученный карбид измельчают в ступке и для получения ацетилена разлагают водой. Схема использованной аппаратуры изображена на рис. 1.

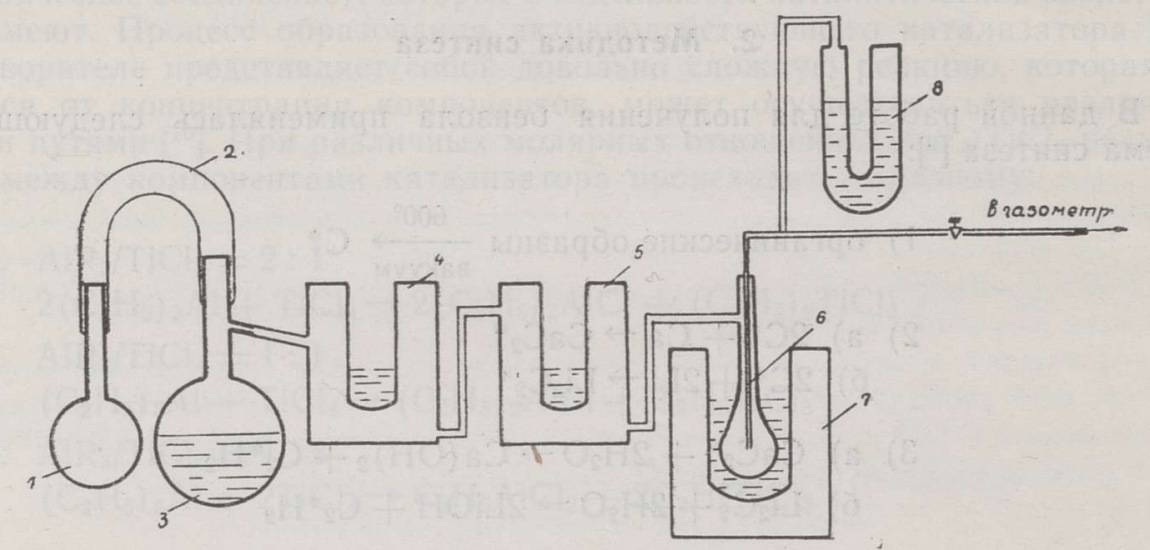

Рис. 1. Схема аппаратуры для разложения карбида: 1 - колба с карбидом; 2 - резиновый шланг; 3 - колба разложения; 4, 5 - металлические ловушки с жидким азотом; 6 - колба для вымораживания ацетилена; 7 - сосуд Дьюара с жидким азотом; 8- манометр.

В колбу 1 помещают измельченный карбид и откачивают воздух из системы. Через резиновую трубку 2 карбид всыпают в колбу 3 , заполненную до половины насыщенным водным раствором хлористого натрия. Так как реакция разложения карбида сильно экзотермическая, колбу 3 следует при больших количествах карбида охлаждать. В противном случае непрореагированный литий, реагируя с горячей водой, может воспламениться. Если разложение проводить путем прибавления воды к карбиду, происходит сильное локальное перегревание сосуда, содержащего карбид.

Выделенный ацетилен вымораживается в металлических ловушках 4 и 5 жидким азотом. По окончании разложения карбида ацетилен сублимируется в колбу 6, которая погружена в сосуд Дьюара 7 с жидким азотом. Затем, после выключения остальной сғстемы, откачивают окклюдированные на ащетилене газовые примеси.

Очищенный ацетилен собирается в газометрах. Поскольку ацетилен значительно растворяется в воде, для наполнения газометров применялся насыщенный водный раствор хлористого натрия.

Содержание ацетилена в полученном газе (по данным анализа) достигает $90-98$ об.\%.

В. Синтез бензола. Была изучена методика синтеза бензола и зависимость выхода продукта от отношения компонентов катализатора и от количества пропущенного ацетилена. 
Очнстка газа и тримеризация ацетилена проводилась при помощи аппаратуры, схема которой приведена на рис. 2. В четырехгор.товую колбу 8 загружают $300-500$ мл перегнанного над Na растворителя ( $\boldsymbol{M - к и - ~}$ лола) и продувают систему для удаления кислорода при энергичном перемешивании аргоном в течение 45-60 мин. Затем, в токе аргона, прибавляют в колбу 8 нужное количество (изо- $\left.{ }_{4} \mathrm{H}_{9}\right)_{3} \mathrm{Al}$, диспергируют его 15 мин. и вводят $\mathrm{TiCl}_{4}$. Перемешивание раствора продолжают при комнатной температуре для активизации катализатора еще 30 мин.

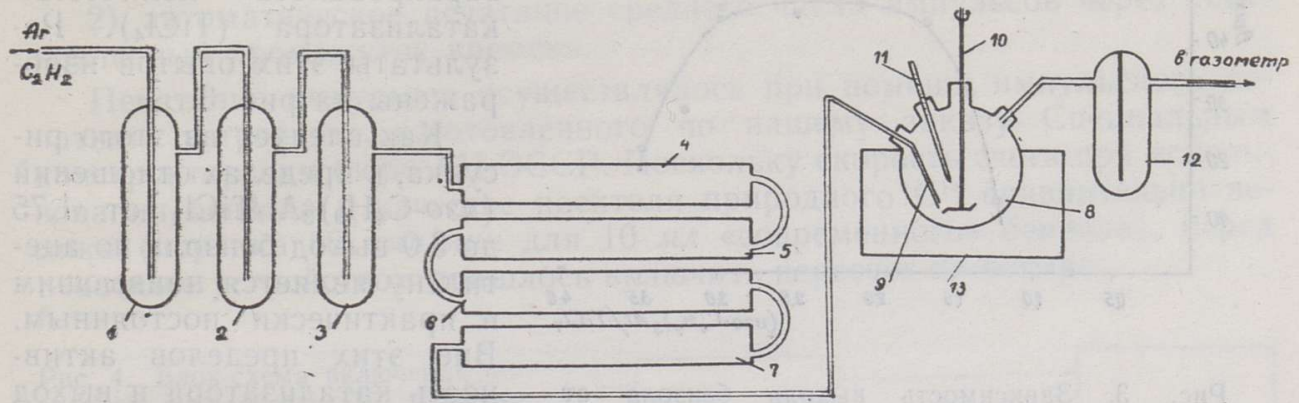

Рис. 2. Схема аппаратуры для тримеризации ацетилена: $I-7-$ поглотители для очистки аргона и ацетилена; 8- реакционный сосуд; 9 - вводная трубка; 10 - мешалка; 11 - термометр; 12 - жидкостный затвор; 13 - охладительный агрегат.

Подача ащетилена проводится при температуре $-10 \pm 2^{\circ}$, которая достигалась при помощи холодильного агрегата 13.

Так как (uзо- $\left.\mathrm{C}_{4} \mathrm{H}_{9}\right)_{2} \mathrm{Al}$ под действием кислорода и влаги разлагается, то применяемый аргон и ацетилен подвергают тщательной очистке путем пропускания их через систему очистки. Последняя состоит из следующих поглотителей: 1 - кислотный раствор $\mathrm{FeCl}_{3}$ и $\mathrm{CuCl}_{2}$ (для очистки $\mathrm{C}_{2} \mathrm{H}_{2}$ от $\mathrm{PH}_{3}$ и $\mathrm{H}_{2} \mathrm{~S}$ ); 2,3 - пирогаллол $A$ в щелочном растворе (для поглошения кислорода); 4 - аскарит, $\mathrm{KOH}$ (для очистки газа от $\mathrm{CO}_{2}$ ) : поглотители 5,6 и 7 , содержащие соответственно $\mathrm{CaCl}_{2}$, силикагель и $\mathrm{P}_{2} \mathrm{O}_{5}$ с $\mathrm{Al}_{2} \mathrm{O}_{3}$, предназначены для осушки газа.

Реакция полимеризации экзотермическая. После пропускания $3-5.2$ ацетилена начинается энергичное поглощение газа, сопровождающееся повышением температуры. После этого скорость пропускания можно увеличить до $20-25$ л/час.

Непрореагировавший газ собирают в газометр и снова подают в систему. Затем вытесняют ацетилен из системы очистки при помощи ар гона. Для разложения катализатора и облегчения выделения бензола в реакционную смесь вводят метанол.*

Из реакционной смеси (колба 8) отгоняют фракцию с температурой кипения до $100^{\circ}$, обрабатывают ее в делительной воронке дистиллированной водой, концентрированной $\mathrm{H}_{2} \mathrm{SO}_{4}$, нейтрализуют раствором $\mathrm{Na}_{2} \mathrm{CO}_{3}$ и снова промывают дистиллированной водой; затем высушивают на́ $\mathrm{CaCl}_{2}$ и выделяют бензол, перегоняя его над металлическим $\mathrm{Na}$. При перегонке использовалась ректификационная колонка с 17-ю теоретическими тарелками.

Физические константы полученного бензола хорошо совпадают со справочными. Кроме того, чистота бензола проверялась при помощи га-

* Метанол образует с бензолом азеотропную смесь, имеющую температуру кипения $58,34^{\circ}$ и содержашую 39,6 вес. ч. метанола. 
зового хроматографа. Получе́нные хроматограммы-показывают отсутствие примесей.

Особое внимание уделялось исследованию влияния отношения катализатора и сокатализатора на выход бензола.

Опыты проводились в следующих условиях: при постоянных количествах ацетилена $(8-10 \Omega)$,

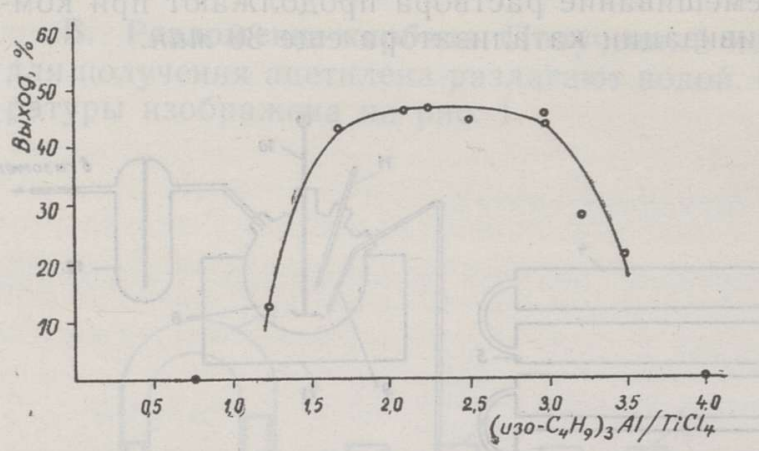
растворителя (350 мл $м$-ксилола) и $\left(\right.$ изо- $\left.\mathrm{C}_{4} \mathrm{H}_{9}\right){ }_{3} \mathrm{Al}(3,92$ г) варьировалось количество катализатора $\left(\mathrm{TiCl}_{4}\right)$. Peзультаты этих опытов изображены на рис. 3.

Как следует из этого рисунка, в пределах отношений $\left(\text { u } 30-\mathrm{C}_{4} \mathrm{H}_{9}\right)_{3} \mathrm{Al} / \mathrm{TiCl}_{4}$ от 1,75 до 3,0 выход бензола по ацетилену является наивысшим и практически постоянным. Вне этих пределов актив-

Рис. 3. Зависимость выхода бензола от ность катализатора и выход весового отношения $\left(\text { изо- } \mathrm{C}_{4} \mathrm{H}_{9}\right)_{3} \mathrm{Al} / \mathrm{TiCl}_{4}$.

бензола падают. При отношениях $1,75-3,0$ четырехвалентный титан восстановлен до двухвалентного, который по питературным данным и содержится в активнодействующем катализаторе. При избытке $\mathrm{TiCl}_{4}$ образуется $\mathrm{RTiCl}_{3}$, и каталитическая активность снижается.

Наряду с бензолом всегда отмечалось образование нерастворимого в реакционной среде полимера.

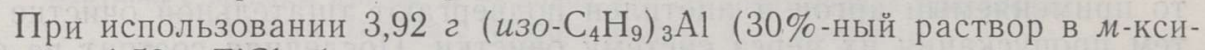
лоле) и 1,53 г $\mathrm{TiCl}_{4}$ был проведен ряд опытов с целью изучения зависимости выхода бензола от количества пропущенного ацетилена. Выяснилось, что при исследованных количествах его (до $50 \Omega$ ) дефицита катализатора не наблюдается. Увеличение количества катализатора к увеличению выхода бензола не приводило.

Поскольку потеря бензола при выделении его из реакционной смеси почти постоянна, процентуальный выход его при повышении количества ацетилена несколько увеличивается. Были достигнуты выходы бензола до $65 \%$.

\section{II. ИЗМЕРЕНИЕ АКТИВНОСТИ ЕСТЕСТВЕННОГО РАДИОУГЛЕРОДА В БЕНЗОЛЕ}

\section{1. Счетная аппаратура}

Регистрация природного радиоуглерода и все методические измерения были осуществлены при помощи одноканальной сцинтилляционной установки, подробная характеристика которой приведена в статье $\left[{ }^{20}\right]$. В качестве фотоэлектронного умножителя был использован специально отобранный экземпляр английской фирмы EMI тип 6097 S/A № 16612. Энергетический эквивалент собственных шумов этого ФЭУ при скорости счета 10 имn/мин составляет 3,5 кэв по шкале $\mathrm{NaJ}(\mathrm{Tl})$ при рабочем напряжении 905 в. 
Қюветы для сцинтиллятора были изготовлены из алюминия с окном из бескалиевого стекла и обеспечивали хорошую светопередачу и низкий фон $\left[{ }^{21}\right]$.

Для защиты от космического излучения и внешней радиоактивности во время счета естественного $\mathrm{C}^{14}$ служили слой свинца толщиной $\sim 12 \mathrm{~cm}$ и ртути $2,5 \mathrm{~cm}$.

С целью выявления и устранения влияния случайных помех применялись два способа автоматического контроля скорости счета:

1) графический, при котором графически изображается время, за которое набирается определенное число импульсов;

2) автоматическое печатание среднего числа импульсов через установленный промежуток времени.

Печатание импульсов осуществлялось при помощи импульсного печатного устройства, изготовленного по нашему заказу Специальным конструкторским бюро АН ЭССР. Поскольку скорость счета при использовании бензола в качестве носителя природного $\mathrm{C}^{14}$ сравнительно велика (порядка $50 \mathrm{umn/мин} \mathrm{для} 10$ мл «современного» бензола), перед печатным устройством пришлось включить пересчет на четыре.

Рис. 4. Блок-схема включения печатного устройства. ПС - пересчетное устройство; $\mathrm{PB}$ - реле времени; ЭР - электромагнитное реле; ИПУ - импульсное печатное устройство.

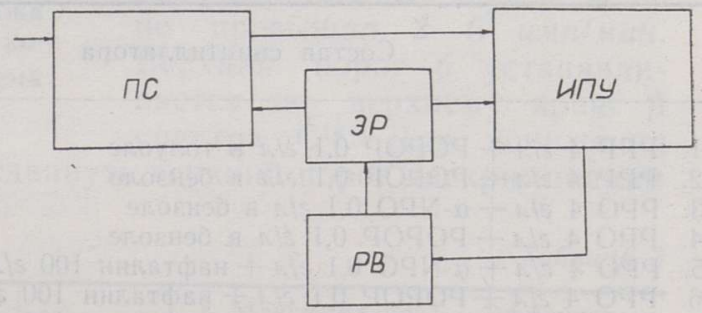

Блок-схема включения печатного устройства показана на рис. 4. Импульсы с выхода дифференциального дискриминатора пересчитывают стандартным пересчетным прибором ПС-64 и поступают в цифровое печатное устройство. Для управления последним применяется реле времени типа «Гамма» (венгерского производства), позволяющее устанавливать интервалы времени счета от 1 сек до 60 мин. По истечении заданного интервала времени контакт автоматически замыкается, расцепляя процесс печатания. После записи печатное устройство вновь принимает исходное положение и заводит реле времени. Во время процесса печатания поступающие импульсы пересчетным прибором не принимаются.

При использовании пересчета на четыре оказалось целесообразным установить интервал времени для каждого счета равным 40 мин. Это позволяет получать цифровые печатные данные, равняющиеся по абсолютным значениям средней скорости счета, т. е. количеству импульсов в минуту.

\section{2. Сцинтиллятор}

Измерения эффективности сцинтилляторов для регистрации естественного $\mathrm{C}^{14}$ в бензоле были проведены методом постоянной скорости счета $\left[{ }^{22}\right]$ по амплитудам выходных импульсов. В качестве возбудителя сцинтилляций в исследуемых растворах был использован внешний $\gamma$-источник $\left(\mathrm{Cs}^{137}\right)$.

С целью увеличения точности измерения эффективности сцинтилляторов уровни запирания интегрального дискриминатора, дающие одн- 
наковую скорость счета для всех образцов, были определены по интегральным спектрам комптоновского рассеяния $\gamma$-квантов $\mathrm{Cs}^{137}$.

Состав исследуемых сцинтилляторов и результаты измерения их эффективности приведены в табл. 2, где для наглядности использованы относительные единицы.

Қак следует из данных табл. 2, относительная эффективность сцинтилляторов, приготовленных на основе бензола, составляет около $80 \%$ эффективности стандартного сцинтиллятора, растворителем которого служил толуол.

Введение нафталина в состав бензоловых сцинтилляторов позволяет повысить световой выход до уровня вышеуказанного стандарта, а добавление в состав сцинтиллятора еще вторичного растворителя - ксилола дает эффективность, превышающую эффективность стандарта. Следует отметить, что вытеснение растворенного в сцинтилляторе кислорода при помощи аргона повышает эффективность сцинтиллятора еще примерно на $20-30 \%$.

Таким образом, наилучшими сцинтилляционными свойствами обладает сцинтиллятор № 7 (см. табл. 2).

Таблица 2

\section{Состав сцинтиллятора}

Относительная эффективность

1. РPР $42 / \Omega+$ POРОР 0,1 2/ $\Omega$ в толуоле

2. PРP $42 / \Omega+$ POPOP 0,1 г/ в бензоле

3. PPO $42 / \Omega+\alpha$-NPO $0,12 / \Omega$ в бензоле

4. PРО $42 / \Omega+$ POPOP 0,1 2/ $/$ в бензоле

5. PPO $42 / \Omega+\alpha$-NPO $0,12 / \Omega+$ нафталин $1002 / \Omega$ в бензоле

6. PРО $42 / \Omega+$ POPOP $0,12 / \Omega+$ нафталин $1002 / \Omega$ в бензоле

7. PРO $42 / \Omega+$ POPOP $0,12 / \Omega+$ нафталин $1002 / \Omega+$ бензол $400 \mu \Omega / \Omega$ в $м$-ксиоле

100
80
80
80
92
98
105

П р и мечание: PPP — паратерфенил; POPOP - 1,4-ди-(5-фенил)-2-оксазолилбензол; РРО - 2,5-дифенилоксазол; $\alpha$-NPO - 2-(1-нафтил)-5-фенилоксазол.

\section{3. Выбор оптимального счетного режима}

На рис. 5 изображены дифференциальные спектры стандартных препаратов бензола. Здесь площадь $N_{0}$ изображает часть $\beta$ спектра, рав-

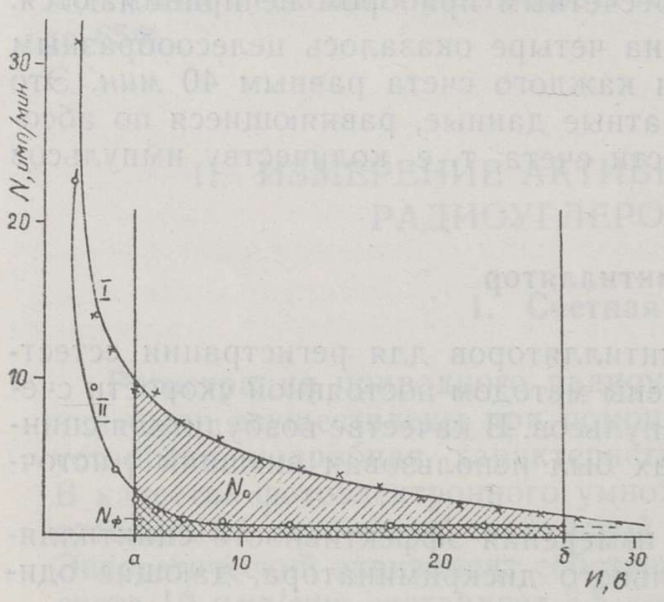
няющуюся скорости счета современного углерода, а площадь $N_{\text {ф }}$ - скорости счета фона.

При выборе оптимального режима, соответствующего максимальному значению отношения $N_{0} / \sqrt{N_{\phi}}$, нижний порог дискриминации $a$ устанавливает-

Рис. 5. Дифференциальные спектры современного (I) и древнего (II) бензола. Площадь $N_{0}-$ скорость счета современного и $N_{\phi}$ - древнего углерода; $a-$ нижний и $\sigma-$ верхний порог дискриминации. 


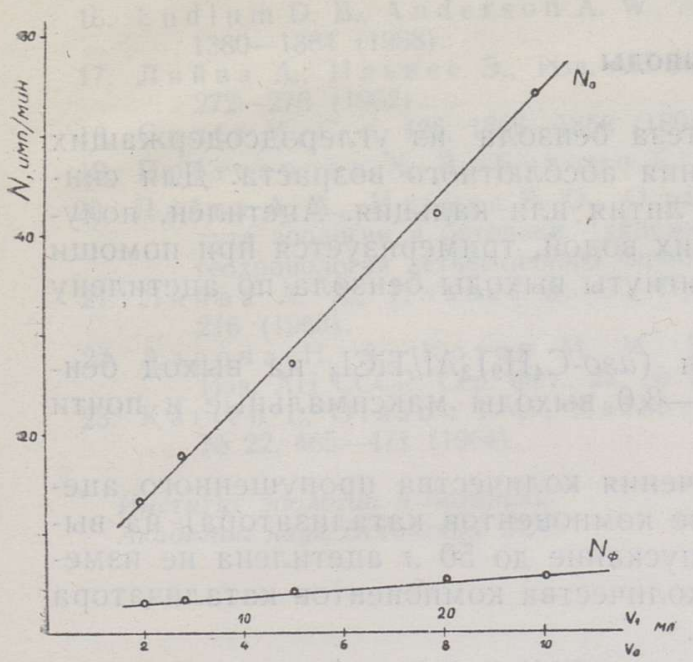

Pнс. 6. Зависимость скорости счета фона $\left(N_{\phi}\right)$ и современного углерода $\left(N_{0}\right)$ от количества бензола $\left(V_{0}\right)$ и общего объема сцинтиллятора $\left(V_{1}\right)$.

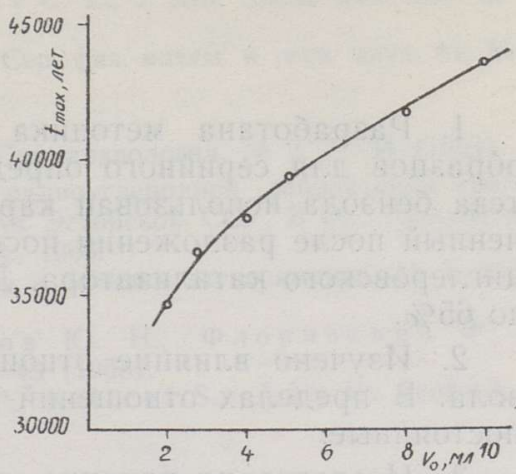

Рис. 7. Зависимость максимально определяемого возраста $\left(t_{\max }\right)$ от количества бензола $\left(V_{0}\right)$.

ся таким образом, чтобы уровень собственных шумов $Ф Э У$ не превышал $2-6$ имn/мuн. Верхний порог $б$ устанавливается по верхнему краю $\boldsymbol{\beta}$ спектра $\mathrm{C}^{14}$. Для понижения фона оказалось целесообразным сдвинуть верхний порог дискриминации в сторону более низких амплитуд.

Таблщца 3

\begin{tabular}{|c|c|c|c|c|c|}
\hline $\begin{array}{l}\text { Ширина } \\
\text { канала, } 8\end{array}$ & $\begin{array}{l}\text { Фон } N_{\phi} \\
\text { имп/мин }\end{array}$ & $\begin{array}{c}\text { Чистый счет } \\
\text { современного } \\
\text { углерода } N_{0} \text {, } \\
\text { имn/мuн }\end{array}$ & $\frac{N_{0}}{\sqrt{N_{\phi}}}$ & $\begin{array}{c}\text { Максимально } \\
\text { определяемый } \\
\text { возраст } t_{\max }, \\
\text { лет }\end{array}$ & $\begin{array}{c}\text { Әффектив- } \\
\text { ность реги- } \\
\text { страции } \\
\text { C }^{14}, \%\end{array}$ \\
\hline $\begin{array}{c}4-14 \\
5,5-26.5 \\
4,7-25,7 \\
3,5-25 \\
2-42\end{array}$ & $\begin{array}{r}5,65 \\
5,26 \\
6,45 \\
8,28 \\
14,1\end{array}$ & $\begin{array}{l}43,5 \\
54,7 \\
59,13 \\
62,5 \\
74,4\end{array}$ & $\begin{array}{l}18,3 \\
23,9 \\
23,3 \\
21,7 \\
19,8\end{array}$ & $\begin{array}{l}41400 \\
43600 \\
43400 \\
42700 \\
42000\end{array}$ & $\begin{array}{l}37 \\
46,5 \\
51 \\
53 \\
64\end{array}$ \\
\hline
\end{tabular}

В табл. 3 прнводятся результаты измерения фона и чистого счета современного углерода в зависнмости от выбора порога канала дифференциального дискриминатора. На основе полученных данных вычислены значения $N_{0} / \sqrt{N_{\phi}}$, являющиеся показатєлями качества счетной системы и величины максимально определяемых возрастов при критерии $4 \delta$ и 48-часовом периоде счета образца и стандартов. Измерения были проведены с 25 мл сцинтиллятора, содержащего 8,1 г углерода в 10 м. синтезированного бензола. В последней графе представлена эффективность регистрации $\mathrm{C}^{14}$, при удельной активности современного углерода $14,24 \pm 0,07$ имn $/$ мин $\left[{ }^{23}\right]$.

Завнсимость скорости счета фона, современного углерода и значений максимально определяемого возраста от количества бензола и общего объема сцинтиллятора изображена на рис. 6 и 7. Из рисунков видно, что скорость счета современного углерода возрастает гораздо быстрее, чем значение фона. Таким образом, при увеличении количества бензола становится практически возможным датирование образцов возрастом до 45000 и даже 50000 лет. Сказанное подтверждает преимущество сцинтилляционного метода по сравнению с газоразрядным методом, что особенно важно при датировании древних образцов. 


\section{Выводы}

1. Разработана методика синтеза бензола из углеродсодержащих образцов для серийного определения абсолютного возраста. Для синтеза бензола использован карбид лития или кальция. Ацетилен, полученный после разложения последних водой, тримеризуется при помощи циглеровского катализатора. Достигнуты выходы бензола по ацетилену до $65 \%$.

2. Изучено влияние отношения $\left(\text { изо- } \mathrm{C}_{4} \mathrm{H}_{9}\right)_{3} \mathrm{Al} / \mathrm{TiCl}_{4}$ на выход бензола. В пределах отношений 1,75-3,0 выходы максимальные и почти постоянные.

3. Исследовано влияние увеличения количества пропущенного ацетилена (при постоянном количестве компонентов катализатора) на выход бензола. Выяснилось, что пропускание до $50 \Omega$ ацетилена не изменяет выхода бензола. Увеличение количества компонентов катализатора также не повышает выход бензола.

4. Описаны применяемая одноканальная сцинтилляционная установка и автоматизация счета природного $\mathrm{C}^{14}$, которое заключается в периодическом печатании среднего числа импульсов через определенный интервал времени.

5. Изучены эффективности некоторых жидких сцинтилляторов для измерения $\mathrm{C}^{14}$ в бензоле.

6. Выработан оптимальный режим регистрации $\mathrm{C}^{14}$, позволяющий при 10 мл бензола определять возраст до 43600 лет, при значении фона 5,26 имn/мин и скорости счета современного углерода 54,73 uмn/мuн.

При соответствующем режиме оказалось возможным регистрировать $\mathrm{C}^{14}$ в бензоле с эффективностью $64 \%$, однако максимально определяемый возраст снижается за счет увеличения фона.

7. Исследованы зависимость скорости счета фона, современного углерода и значений максимального определяемого возраста от количества бензола и общего объема сцинтиллятора.

\section{ЛИТЕРА Т У РА}

1. Pringle R. W., Turchinetz W., Funt B. L., Rev. Scient. Instrum., 26, No. 9, $859-865$ (1955).

2. Ли й в а А. А., Геохимия, № 8, 710-712 (1961).

3. Me ye r R., Ber., 45, 1609-1613 (1912).

4. Zelinsky N., Ber. 57, 264-276 (1924).

5. Reppe W., Chemie und Technik Acetylen-Druck-Reaktionen, Weinheim, 1952.

6. Shapiro J., We is s M. G., J. Am. Chem. Soc., 79, No. 12, 3294 (1957)

7. Tamers M. A., Stipp J. J., Collier J., Geochim. et Cosmochim. Acta, 24, $266-275(1961)$.

8. Lutz E. F., J. Am. Chem. Soc., 83, 2551-2556 (196i).

9. Старик И. Е., Арсланов Х. А., Кленер И. Р., Радиохимия, 5, № 2, $198-205$ (1963).

10. Bermann C., Bestian H., Angew. Chemie, 71, No. 17, 19-21 (1959).

11. Saltmann W. M., Gibbs W. E., Lal J., J. Am. Chem. Soc., 80, No. 21, $5615-5622(1958)$.

12. М а к о в ец к и й К. Л., Циклическая тримеризация ацетиленов в присутствии комплексных металлоорганических катализаторов, Автореферат, М., 1964.

13. Franzus B., Canterino P. J., Wickliffe R. A., J. Am. Chem. Soc., 81, No. 6,1514 (1959).

14. М а рк Г., Г е й л о р д Н., Линейные и стереорегулярные полимеры, М., 1962.

15. B a d i n E. J., J. Am. Chem. Soc., 80, No. 24, 6545-6548 (1958). 
16. Ludlum D. B., Anderson A. W., Ashby C. E., J. Am. Chem. Soc., 80, No. 6, $1380-1384(1958)$.

17. Л и й в а А., Ильв е с Э., Изв. АН ЭССР. Сер. физ.-матем. и техн. наук, 11, № 4, $272-276(1962)$

18. Guntz M., C. r., 126, $1866 \longrightarrow 1868$ (1898).

19. Протопопов Х. В., Бутомо С. В., Сов. археология, № 2, 7-34 (1959).

20. Л ий в а А. А., Ильв ес Э. О., О работе радиоуглеродной лаборатории Института зоологии и ботаники Академии наук Эстонской ССР, В сб.: Абсолютная геохронология четвертичного периода, М., 1963.

21. Л и й в а А. А., И ль в е с Э. О., Приборы и техника эксперимента, № 5, 215216 (1963)

22. Адрова Н. А., Котон М. М., Панов Ю. Н., Флоринский Ф. С., Изв. АН СССР. Сер. физ., 22, № 1, 4r-43 (1958).

23. Karlen I., Olss on I. U., Kallberg P., Kilicci S., Arkiv för geofysik, 4, № 22, 465-471 (1964).

Ннститут зоологии и ботаники Академии наук_Эстонской ССР
Поступила в редакцию $8 /$ VI 1965

\section{J.-M. PUNNING, A. LIIVA, E. ILVES}

\section{LOODUSLIKU RADIOAKTIIVSE SÜSINIKUGA ABSOLUUTSE VANUSE MÄÄRAMISE TÄIUSTATUD METOODIKA}

Käesolevas töös käsitletakse ENSV TA Zooloogia ja Botaanika Instituudis rakendatavat täiustatud absoluutse vanuse määramise metoodikat, mille puhul loodusliku radioaktiivse süsiniku $\left(\mathrm{C}^{14}\right)$ kandjana kasutatakse dateeritavatest objektidest sünteesitud benseeni. järgi:

Benseeni süntees looduslikest orgaanilistest objektidest teostatakse järgmise skeemi

1. Proov $\underset{\text { vaakuum }}{\stackrel{600^{\circ} \mathrm{C}}{\longrightarrow}} \mathrm{C}^{*}$

2. a) $2 \mathrm{C} *+\mathrm{Ca} \stackrel{1000^{\circ} \mathrm{C}}{\longrightarrow} \mathrm{CaC}^{*}$

b) $2 \mathrm{C}^{*}+2 \mathrm{Li} \stackrel{500^{\circ} \mathrm{C}}{\longrightarrow} \mathrm{Li}_{2} \mathrm{C}_{2}^{*}$

3. a) $\mathrm{CaC}_{2}{ }_{2}+2 \mathrm{H}_{2} \mathrm{O} \rightarrow \mathrm{Ca}(\mathrm{OH})_{2}+\mathrm{C}_{2}{ }_{2} \mathrm{H}_{2}$

b) $\mathrm{Li}_{2} \mathrm{C}^{*}+2 \mathrm{H}_{2} \mathrm{O} \rightarrow 2 \mathrm{LiOH}+\mathrm{C}_{2}{ }_{2} \mathrm{H}_{2}$

4. $3 \mathrm{C}_{2}{ }_{2} \mathrm{H}_{2} \frac{\left(\text { iso- } \mathrm{C}_{4} \mathrm{H}_{9}\right)_{3} \mathrm{Al}-\mathrm{TiCl}_{4}}{-10^{\circ} \mathrm{C}} \longrightarrow \mathrm{C}_{6}^{*} \mathrm{H}_{6}$

Uuriti atsetüleeni trimerisatsiooni saagist sōltuvalt katalüsaatori komponentide kontsentratsioonist ja läbijuhitud atsetüleeni hulgast. Vanemikus (iso- $\left.\mathrm{C}_{4} \mathrm{H}_{9}\right)_{3} \mathrm{Al} / \mathrm{TiCl}_{4}=$ $=1,75-3,0$ on benseeni saagis maksimaalne (kuni $65 \%$ atsetüleeni järgi).

Loodusliku $\mathrm{C}^{14}$ aktiivsuse mõõtmine toimus ühekanalilise stsintillatsioonloendajaga. Tulemused registreeriti automaatselt, kusjuures perioodiliselt trükiti lindile loenduskiiruse keskmine numbriline väärtus.

Mõõdeti erineva koostisega stsintillaatorite efektiivsust, kusjuures dateerimisel kasutati stsintillaatorit koostisega (7) (vt. tabel 2).

Töötati välia optimaalne loendusrežiim $\mathrm{C}^{14}$ määramiseks, mis $10 \mathrm{ml}$ uuritava benseeni puhul võimaldab dateerida kuni 43600 aasta vanuseid objekte fooni väärtusel $5,26 \mathrm{imp} / \mathrm{min}$ ja tänapäeva süsiniku loenduskiirusel $54,73 \mathrm{imp} / \mathrm{min}$.

Uuriti fooni $\left(N_{\phi}\right)$, tänapäeva süsiniku loenduskiiruse $\left(N_{0}\right)$ ja maksimaalselt määratava vanuse $\left(t_{\max }\right)$ sõltuvust kasutatud benseeni ja sellele vastava stsintillaatori kogusest (vt. joon. 6). 


\section{ERGÄNZUNG DER REGISTRIERMETHODIK DES NATUR- -RADIOKOHLENSTOFFES ZWECKS ABSOLUTER ALTERSBESTIMMUNG}

In vorliegender Arbeit wird die im Institut für Zoologie und Botanik der Akademie der Wissenschaften der Estnischen SSR angewandte Methodik der Absolutdatierung mit Hilfe des Radiokohlenstoffes behandelt, wobei als Träger des Natur-Radiokohlenstoffes das aus dem Untersuchungsmaterial synthetisierte Benzol verwendet wurde.

Die Benzolsynthese aus dem Untersuchungsmaterial (mit Ausnahme von Karbonaten) verläuft nach folgendem Schema:

$$
\begin{aligned}
& \text { 1. Probe } \underset{\text { vakuum }}{\stackrel{600^{\circ} \mathrm{C}}{\longrightarrow}} \mathrm{C}^{*} \\
& \text { 2. a) } 2 \mathrm{C}^{*}+\mathrm{Ca} \stackrel{1000^{\circ} \mathrm{C}}{\longrightarrow} \mathrm{CaC}_{2} \\
& \text { b) } 2 \mathrm{C}^{*}+2 \mathrm{Li} \stackrel{500^{\circ} \mathrm{C}}{\longrightarrow} \mathrm{Li}_{2} \mathrm{C}_{2} \\
& \text { 3. a) } \mathrm{CaC}_{2}+2 \mathrm{H}_{2} \mathrm{O} \rightarrow \mathrm{Ca}(\mathrm{OH})_{2}+\mathrm{C}_{2}^{*} \mathrm{H}_{2} \\
& \text { b) } \mathrm{Li}_{2} \mathrm{C}_{2}+2 \mathrm{H}_{2} \mathrm{O} \rightarrow 2 \mathrm{LiOH}+\mathrm{C}_{2}^{*} \mathrm{H}_{2} \\
& \text { 4. } 3 \mathrm{C}_{2}{ }_{2} \mathrm{H}_{2} \stackrel{\left(\text { iso- }-\mathrm{C}_{4} \mathrm{H}_{9}\right)_{3} \mathrm{Al}-\mathrm{TiCl}_{4}}{\longrightarrow} \mathrm{C}_{6}{ }_{6} \mathrm{H}_{6}
\end{aligned}
$$

Es wurde die Abhängigkeit der Benzolausbeute von der Konzentration der Komponenten des Katalysators und vom Volumen des durchgeleiteten Azetylens untersucht. Beim Verhältnis (iso- $\left.\mathrm{C}_{4} \mathrm{H}_{9}\right)_{3} \mathrm{Al} / \mathrm{TiCl}_{4}=1,75-3,0$ ist die Benzolausbeute maximal und annähernd konstant (bis $65 \%$ nach Azetylen berechnet).

Die Messungen wurden mit einem Einkanal-Szintillationszähler durchgeführt. Das Registrieren der Zählraten erfolgte automatisch.

An Hand von Vergleich verschiedener Szintillatoren wurde für das Registrieren des Radiokohlenstoffes ein optimales Zählregime ermittelt, welches mit $10 \mathrm{ml}$ Benzol ein Maximalalter von 43600 Jahren ergibt. Hierbei beträgt der Nulleffekt 5,26 Impulse pro Minute und die Nettozählrate des Rezentstandards - 54,73 Impulse pro Minute.

Es wurde auch die Abhängigkeit des Nulleffektes $\left(N_{\phi}\right)$, der Nettozählrate des Rezentstandards $\left(N_{0}\right)$ und des Maximalalters $\left(t_{\max }\right)$ von der Benzolmenge und von dem entsprechenden Szintillatorvolumen untersucht. 